\title{
Morphine Inhibits Sleep-Promoting Neurons in the Ventrolateral Preoptic Area Via Mu Receptors and Induces Wakefulness in Rats
}

\author{
Qin Wang ${ }^{1,2}$, Xiao-Fang Yue ${ }^{1,2}$, Wei-Min Qu*,2,3, Rong Tan', Ping Zheng ${ }^{1,3}$, Yoshihiro Urade ${ }^{4}$ and \\ Zhi-Li Huang*, , 2,3
}

'State Key Laboratory of Medical Neurobiology, Fudan University, Shanghai, China; ${ }^{2}$ Department of Pharmacology, Shanghai Medical College, Fudan University, Shanghai, China; ${ }^{3}$ Institutes of Brain Science, Fudan University, Shanghai, China; ${ }^{4}$ Department of Molecular Behavioral Biology, Osaka Bioscience Institute, Osaka, Japan

\begin{abstract}
Morphine is the most efficacious and widely prescribed treatment for pain. However, it decreases the total amount of deep sleep and rapid eye movement sleep in humans. Acute morphine administration at low doses causes wakefulness in animal models. To clarify the mechanism by which morphine affects sleep-wake behavior, we investigated the effects of morphine on the sleep-promoting neurons of the ventrolateral preoptic area (VLPO), a putative sleep-active nucleus, using in vitro brain slices by the patch-clamp technique. We also examined the effects of morphine on sleep-wake profiles after administration of opioid receptor antagonist to the VLPO using EEG and electromyogram recordings in freely moving rats. The results showed that morphine inhibited the firing rate of sleep-promoting neurons and hyperpolarized their membrane potentials without affecting interneurons in the VLPO. Morphine-induced hyperpolarization of membrane potentials could be reversed by, D-Phe-Cys-Thr-D-Trp-Orn-Thr-Pen-Thr-NH2 (CTOP), a mu receptor antagonist, in the presence of tetrodotoxin. However, after the mu receptors were blocked by CTOP, morphine still suppressed the firing of the sleeppromoting neurons. This effect was antagonized by nor-BIN, a kappa receptor antagonist. Activation of kappa receptor by $\mathrm{U} 50488 \mathrm{H}$ inhibited the firing of the sleep-promoting neurons. These results indicate that morphine could inhibit the activity of sleep-promoting neurons in the VLPO through mu and kappa receptors. EEG recordings revealed that morphine injected subcutaneously induced arousal in a dose-dependent manner. CTOP microinjected into VLPO antagonized the arousal effects of morphine, but nor-BIN did not. However, CTOP alone was not associated with any changes in the physiological sleep-wake cycle. Taken together, these findings clearly indicate that morphine inhibits sleep-promoting neurons in the VLPO by affecting mu receptors and so induces wakefulness in rats. Neuropsychopharmacology (2013) 38, 79I-80I; doi:I0.1038/npp.20I2.244; published online I6 January 2013
\end{abstract}

Keywords: morphine; opioid receptor; VLPO; wakefulness

\section{INTRODUCTION}

Morphine is the most efficacious and widely prescribed treatment for pain. Unfortunately, it has many side effects, including sleep disruption (Raehal and Bohn, 2005). In healthy human volunteers, clinically relevant doses of morphine increase light sleep (stage 2) but decrease deep sleep (stage 3 and 4 ) and rapid eye movement (REM) sleep (Dimsdale et al, 2007; Shaw et al, 2005).

The mechanisms underlying morphine-induced sleep disruption remain debatable. Some evidence regarding affected brain regions and neurotransmitters by which morphine may exert its effects on sleep-wake behavior has

*Correspondence: Dr W-M Qu or Professor Z-L Huang, Department of Pharmacology and State Key Laboratory of Medical Neurobiology, Shanghai Medical College of Fudan University, Medical College Road 138, Shanghai 200032, China. Tel/Fax: + 8621 54237I03,

E-mail: quwmjp@yahoo.com.cn or huangzljp@yahoo.com.cn

Received 9 August 2012; revised 15 November 2012; accepted 19 November 2012; accepted article preview online 30 November 2012 emerged. In cats, microinjection of morphine into the medial pontine reticular formation (mPRF) has been found to significantly inhibit REM sleep in a dose- and sitedependent manner (Keifer et al, 1992). Morphine-mediated REM sleep inhibition is localized to a specific region of the PRF, the gigantocellular tegmental field (GTF). The release of acetylcholine in the pontine GTF has been found to be significantly depressed by systemically administered morphine (Lydic et al, 1993). Cholinergic neurotransmission in the GTF is known to have a role in REM sleep generation (Lydic et al, 1991). In this way, reduction of the release of acetylcholine in the pontine GTF is one mechanism by which morphine inhibits REM sleep. In rats, morphine has been found to cause a concentrationdependent decrease in GABA levels of the oral part of the pontine reticular nucleus (PnO; Watson et al, 2007). Morphine may disrupt sleep by decreasing GABAergic transmission in the PnO. The median preoptic nucleus (MnPO), tuberomammillary nucleus (TMN), and lateral hypothalamus (LH) may be involved in the regulation of 
morphine on sleep-wakefulness behavior. $\mathrm{Mu}$ receptor agonists were found to hyperpolarize some of the neurons in the MnPO in rats (Henry et al, 2008). In in vitro brain slices, morphine has been found to excite TMN histaminergic neurons and inhibit orexin neurons (Eriksson et al, 2000; Li and van den Pol, 2008).

The ventrolateral preoptic nucleus (VLPO) has been shown to have an important somnogenic role in the CNS (Lu et al, 2002; Lu et al, 2000; Sherin et al, 1998; Sherin et al, 1996; Szymusiak et al, 1998). In the VLPO, $85 \%$ of sleeppromoting neurons express mu and kappa receptor mRNA (Greco et al, 2008). The VLPO may therefore function as the neuroanatomic substrate by which morphine mediates the effects of these neurons on sleep.

To evaluate one possible role of the VLPO in mediating the effects of morphine on sleep-wakefulness behavior, we determined the effects of morphine on the excitability of the VLPO neurons in in vitro brain slices, and also clarified the role of the VLPO in the arousal effects of morphine at a systemic level through the microinjection of opioid receptor antagonist into the VLPO before subcutaneous injection of morphine.

\section{MATERIALS AND METHODS}

\begin{abstract}
Animals
Male Sprague-Dawley rats, $14-21$ days old weighing 30-40 $\mathrm{g}$, were used for the electrophysiological experiment. And 6-8week-old rats weighing 250-300 $g$ were used for EEG recording. All rats were obtained from the Laboratory Animal Center, Chinese Academy of Sciences (Shanghai, China). The animals were housed individually at an ambient temperature of $22 \pm 0.5{ }^{\circ} \mathrm{C}$ with a relative humidity of $60 \pm 2 \%$ and an automatically controlled 12 -h light/12-h dark cycle (lights on at 0700 hours, illumination intensity $\approx 100$ lux). They had free access to food and water. All experimental procedures involving animals were approved by the Medical Experimental Animal Administrative Committee of Shanghai Medical College, Fudan University. All efforts were made to minimize animal suffering or discomfort and reduce the number of animals used.
\end{abstract}

\section{Chemicals}

(-) - Norepinephrine (NA), D-Phe-Cys-Thr-D-Trp-OrnThr-Pen-Thr-NH2 (CTOP), trans-( \pm )-3,4-dichloro- $N$ methyl- $N$-(2-[1-pyrrolidinyl]cyclohexyl) benzeneacetamide $(\mathrm{U} 50488 \mathrm{H})$, norbinal -torphimine (nor-BNI), and tetrodotoxin (TTX) were obtained from Sigma (Saint Louis, MO). All chemicals were dissolved in artificial cerebrospinal fluid (ACSF).

\section{Electrophysiology}

Slice preparation. Electrophysiological experiments were performed on slices retrieved from Sprague-Dawley rats 14-21 days old. Rats were decapitated and brain tissue was disassociated from the skull. VLPO was identified according to the stereotaxic coordinates (Paxinos and Watson, 2007). Coronal basal forebrain/preoptic slices $(300 \mu \mathrm{m}$ thick) containing VLPO were cut using a vibratome (Leica VT
1000S, Nussloch, Germany) in ice-cold glycerol-based ACSF (GACSF) containing (in $\mathrm{mM}$ ): glycerol, $260 ; \mathrm{KCl}, 5 ; \mathrm{KH}_{2} \mathrm{PO}_{4}$, 1.25; $\mathrm{MgSO}_{4}, 1.3 ; \mathrm{CaCl}_{2}, 0.5 ; \mathrm{NaHCO}_{3}, 20$; and glucose, 10 . GACSF was first saturated with $95 \% \mathrm{O}_{2}-5 \% \mathrm{CO}_{2}$ (carbogen) before use. Slices were allowed to recover for at least $1 \mathrm{~h}$ in a holding chamber at $32{ }^{\circ} \mathrm{C}$ in carbogen-saturated regular ACSF, which has the same composition as GACSF except that glycerol is replaced with $125 \mathrm{mM} \mathrm{NaCl}$ and the concentration of $\mathrm{CaCl}_{2}$ is adjusted to $2.4 \mathrm{mM}$. (modified from Gallopin et al, 2000; and Ye et al, 2006).

Patch-clamp recordings in the whole-cell configuration. The patch electrodes were pulled from borosilicate glass capillaries $(1.5 \mathrm{~mm}$ o.d., $0.86 \mathrm{~mm}$ i.d., Harvard Apparatus, France) on a Brown-Flaming micropipette puller (Model P-97, Sutter Instrument, Novato, CA). They had a resistance of 4-6 $\mathrm{M} \Omega$ when filled with the pipette solution containing (in $\mathrm{mM}$ ): potassium gluconate, $130 ; \mathrm{KCl}, 10 ; \mathrm{MgCl}_{2}, 2$; HEPES, 10; MgATP, 2; and NaGTP, 0.3, with pH adjusted to 7.3 with $\mathrm{KOH}$. A single coronal slice was transferred into a 0.4-ml recording chamber, where it was held down by a platinum ring. Carbogenated ACSF flowed through the bath $(2 \mathrm{ml} / \mathrm{min})$. VLPO neurons were identified under visual guidance using upright microscope (BX-51, Olympus, Japan) with a $\times 40$ water immersion objective lens. The image was detected with an IR-sensitive CCD camera and displayed on a monitor. Neurons were current clamped to record spontaneous action potentials and/or membrane potentials. The series resistance (3-5M $\Omega$ ) and input resistance (300-400 M $\Omega$ ) were monitored throughout the cell recording, and data were discarded when either of the two resistances changed by $>20 \%$.

Extracellular recordings in cell-attached configuration. This recording configuration was used to study the effects of one or multiple drug applications on a single VLPO cell. In contrast to intracellular and whole-cell patch-clamp configurations, this mode allows stable extracellular recordings of healthy neurons for the long periods of time necessary to complete pharmacological experiments. Olympus upright microscope and IR-sensitive CCD camera were used to locate the supposed sleep-promoting neurons in the VLPO. These neurons usually showed a multipolar triangular shape. Cell-attached recordings were made from the soma with patch micropipettes (5-8 M $\Omega$ ) filled with ACSF. During extracellular recordings in cell-attached configuration, a seal resistance was kept $<15 \mathrm{M} \Omega$ to prevent cell damage and mechanical stimulation (modified from Gallopin et al, 2004, 2005).

For all electrophysiological experiments, the data acquisition was performed using an Axon 200B amplifier (Molecular Devices, Union City, CA) connected to a Digidata 1440A A/D converter (Molecular Devices). Signals were amplified and collected on an HP-XP-1 GHz PC using pCLAMP 10.2 data acquisition software. Data were filtered at $1 \mathrm{kHz}$ and sampled at $5 \mathrm{kHz}$.

\section{Microinjection and Sleep Monitoring}

EEG/EMG, cannula, and sleep recordings. Under pentobarbital anesthesia $(50 \mathrm{mg} / \mathrm{kg}$, i.p.), the rats were implanted 
with electrodes for polysomnographic recording of EEG and electromyogram (EMG) and two guide cannulae (30 gauge, PlasticOne, Roanoke, VA) for drug administration (Hong et al, 2005; Greco et al, 2008). The two guide cannulae were inserted stereotaxically at positions of anteroposterior (AP) $-0.5 \mathrm{~mm}$; left-right $\pm 1.0 \mathrm{~mm}$; dorsoventral $-7.0 \mathrm{~mm}$ from bregma; $0.5 \mathrm{~mm}$ above the VLPO according to the atlas (Paxinos and Watson, 2007), as shown in Figure 5a and b. The two cannulae and EEG electrodes were fixed to the skull with dental cement and three stainless steel screws for anchorage. Two stainless steel wire electrodes were placed in the neck muscles for EMG recordings. During recovery from surgery, the animals were kept on a heating pad, where they were monitored for irregularities in respiration, postoperative pain, and the ability to return to sternal recumbency. Each rat was allowed 10 days for recovery. Then the EEG and EMG recordings were carried out by means of a slip ring designed so that the behavioral movement of the rats would not be restricted. The rats were housed individually in transparent barrels and habituated to the recording cable for 3-4 days before polygraphic recording.

Sleep analysis. Cortical EEG and EMG signals were amplified, filtered (EEG, 0.5-30 Hz; EMG, 20-200 Hz), digitized at a sampling rate of $128 \mathrm{~Hz}$, and recorded using SleepSign (Kissei Comtec, Nagano, Japan) as described previously (Huang et al, 2003; Kohtoh, 2008). When complete, polygraphic recordings were automatically scored offline at 4-s epochs as wakefulness, REM sleep, and NREM sleep using SleepSign according to standard criteria (Huang et al, 2001, 2003; Wang et al, 2012). Defined sleep-wake stages were examined visually and corrected, if necessary.

\section{Histological Localization of Microdialysis and Microinjection Sites}

Microinjection sites were determined according to the following procedure. After a minimum of 2 days postexperiment, animals were deeply anesthetized and decapitated. Brains were rapidly removed, frozen, and serially sectioned $(40 \mu \mathrm{m}$ thick) with a Leica CM 3050S cryostat (Leica Microsystems). Coronal sections spanning the VLPO were mounted on chrome alum-coated slides, dried overnight, fixed in paraformaldehyde vapor $\left(80{ }^{\circ} \mathrm{C}\right)$, and stained with cresyl violet. All sections containing microinjection sites were compared with a rat brain atlas to determine the three-dimensional coordinates $(\mathrm{mm})$ of the site relative to bregma (Paxinos and Watson, 2007). Only experiments in which the tip of the microinjection cannula was located above the VLPO were included in data analysis (Figure 5a and $b)$.

\section{Statistical Analysis}

All results were expressed as means \pm SEM $(n=4-6)$. During each hour, the amount of time spend in each stage was measured, and histograms showing sleep and wakefulness were analyzed. Comparisons of the differences in measured data among multiple groups were analyzed using one-way ANOVA followed by Fisher's probable least-squares difference (PLSD) testing. In all cases, $P<0.05$ was taken as the level of significance.

\section{RESULTS}

\section{Effects of Subcutaneous Administration of Morphine on} Wakefulness in Rats

Morphine was subcutaneously injected into rats at 0900 hours at a dose of $0.3,1$, or $3 \mathrm{mg} / \mathrm{kg}$, and the sleep-wake pattern of the animals was examined. When morphine at a dose of $1 \mathrm{mg} / \mathrm{kg}$ was injected on the experimental day, the animal spent more time awake than on control days (Figure 1a and $\mathrm{b}$ ). The increase in wakefulness and decrease in NREM sleep lasted for $2 \mathrm{~h}$ after the injection (Figure 1c). The total time spent awake and in NREM and REM sleep during the $3 \mathrm{~h}$ following morphine injection was calculated (Figure 1d). Morphine at a dose of $0.3 \mathrm{mg} / \mathrm{kg}$ had no effects on the sleep-wakefulness pattern (for wakefulness, $105.26 \pm 8.41 \mathrm{~min} v s 106.82 \pm 13.91 \mathrm{~min}$ for the saline injection, $P=0.92$; for NREM sleep, $68.03 \pm 7.35 \mathrm{~min} v s 68.10 \pm$ $11.65 \mathrm{~min}, P=0.996$; and for REM sleep, $6.70 \pm 1.91 \mathrm{~min} v s$ $3.80 \pm 2.45 \mathrm{~min}, \quad P=0.61 ; n=6)$. Morphine at $1 \mathrm{mg} / \mathrm{kg}$ increased wakefulness by $64.3 \% \quad(145.70 \pm 20.58 \mathrm{~min} v \mathrm{~s}$ $88.70 \pm 13.98 \mathrm{~min}$ for the saline injection, $P<0.01$ ), with a decrease in NREM and REM sleep of $62.3 \%(31.27 \pm$ $7.51 \mathrm{~min}$ vs $82.98 \pm 12.71 \mathrm{~min}$ for the saline injection, $P<0.001)$ and $57.8 \%(3.04 \pm 0.89 \mathrm{~min} v s 7.22 \pm 2.04 \mathrm{~min}$ for the saline injection, $P=0.079)$, respectively $(n=7)$. Similarly, after morphine injection at a dose of $3 \mathrm{mg} / \mathrm{kg}$ in the animals, wakefulness increased by $71.5 \%$ (163.37 $\pm 7.30 \mathrm{~min}$ vs $95.29 \pm 14.80 \mathrm{~min}$ for the saline injection, $P<0.01$ ), and NREM and REM sleep decreased by 79.1\% (16.02 $\pm 6.91 \mathrm{~min}$ vs $76.70 \pm 12.69 \mathrm{~min}$ for the saline injection, $P<0.001)$ and $92.4 \%(0.61 \pm 0.43 \mathrm{~min}$ vs $8.04 \pm 2.40 \mathrm{~min}$ for the saline injection, $P<0.01)$, respectively $(n=8)$. These results indicated that morphine increased wakefulness and decreased NREM and REM sleep in a dose-dependent manner (for wakefulness, $F(2,18)=14.61, P<0.001$; for NREM and REM sleep, $\mathrm{F}(2,18)=13.81, P<0.001$, and $\mathrm{F}(2,18)=7.70, P<0.01$, respectively).

\section{Identification and Classification of the VLPO Neurons in in vitro Brain Slices}

According to the previous study (Gallopin et al, 2000), we divided the VLPO neurons into sleep-promoting neurons and the interneurons by their responses to NA. The neurons inhibited by NA $(10 \mu \mathrm{M})$ were identified as the sleeppromoting neurons, which were usually multipolar triangular cells (Figure 2a), and the neurons excited by NA were interneurons, which had bipolar fusiform shapes (Figure 2c). It should be pointed out that not all triangular cells in the VLPO were inhibited by NA, and some nontypical triangular cells exhibited an inhibitory effect in response to NA. In further study, we found that NAinhibited triangular neurons (sleep-promoting neurons) showed significant low-threshold spikes (LTSs; $n=11$, Figure 2b), whereas NA-excited neurons (the interneurons) had no LTSs $(n=4$, Figure $2 \mathrm{~d})$. Therefore, only typical triangular neurons in the VLPO inhibited by NA $(10 \mu \mathrm{M})$ were identified as the sleep-promoting neurons and 

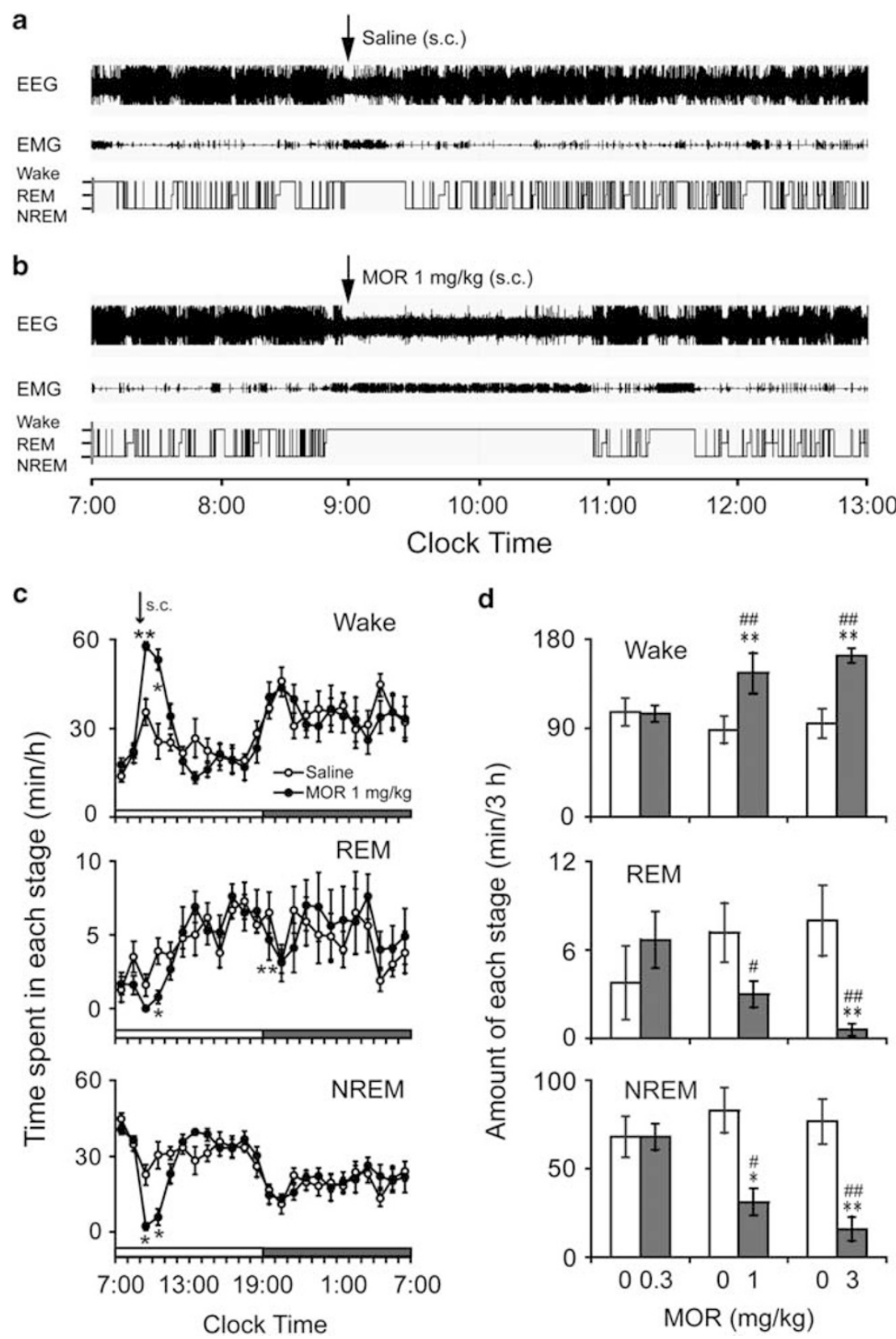

Figure I Sleep-wake profiles with subcutaneous morphine injection in rats. (a, b) Typical examples of polygraphic recordings and corresponding hypnograms in a rat treated with saline or morphine at a dose of I mg/ $/ \mathrm{kg}$. (c) Time course of wakefulness and NREM and REM sleep in rats treated with saline or morphine $(\mathrm{I} \mathrm{mg} / \mathrm{kg}$ ). Each circle represents the hourly mean amounts of each stage. Open and filled circles show the profiles of the saline and morphine treatments, respectively. (d) Amount of wakefulness and REM and NREM sleep for a 3-h period after the injection of saline or morphine. Open and filled bars indicate the profiles of the saline and morphine treatments. $* P<0.05$, ** $P<0.01$, significantly different from the saline treatment as assessed by paired t-test. ${ }^{\#} P<0.05 ;{ }^{\#} P<0.0$ I, significantly different from morphine treatment at $0.3 \mathrm{mg} / \mathrm{kg}$, as assessed by ANOVA followed by Fisher's PLSD test. Values are means \pm SEM $(n=6-8)$.

recorded in the study. In the following electrophysiological experiments, to differentiate between sleep-promoting neurons and the interneurons, the response to NA for each neuron was first tested before further examination on other chemicals.

\section{Effects of Morphine on the Firing of VLPO}

\section{Sleep-promoting Neurons in in vitro Brain Slices}

We studied the effects of morphine on the activity of the VLPO neurons in acute brain slice of rats (Figure 3). Under current-clamp conditions, bath application of morphine at a concentration of $10 \mu \mathrm{M}$ inhibited the firing and hyperpolarized membrane potentials by $8.31 \pm 0.91 \mathrm{mV}$ (from $-44.50 \pm 1.41$ to $-52.81 \pm 1.82 \mathrm{mV}, P<0.001$, respectively, $n=13$ out of 17 , Figure $3 a$ ). After washout, this effect was reversed in minutes, followed by long-lasting inhibition. Morphine at a concentration of $30 \mu \mathrm{M}$ inhibited the firing and hyperpolarized membrane potentials by $9.00 \pm$ $1.98 \mathrm{mV}$ (from $-42.20 \pm 1.37$ to $-51.20 \pm 2.93 \mathrm{mV}$, $P<0.01$, respectively, $n=6$, Figure $3 \mathrm{~b}$ ). Morphine at $100 \mu \mathrm{M}$ inhibited the firing and hyperpolarized membrane 
a

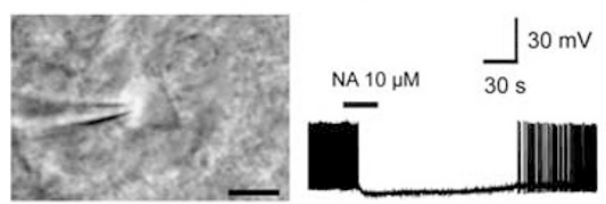

c

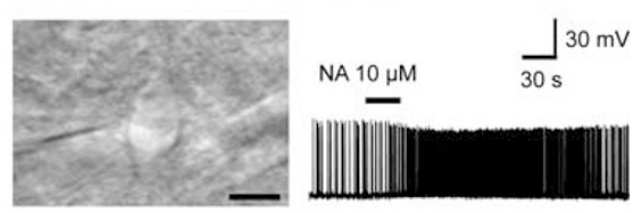

b

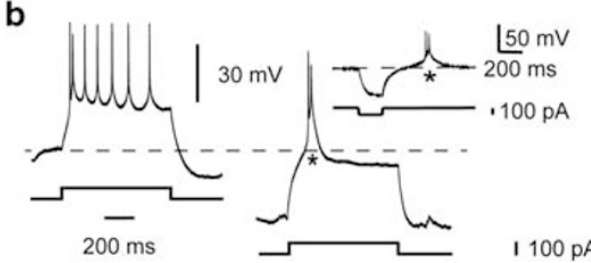

d

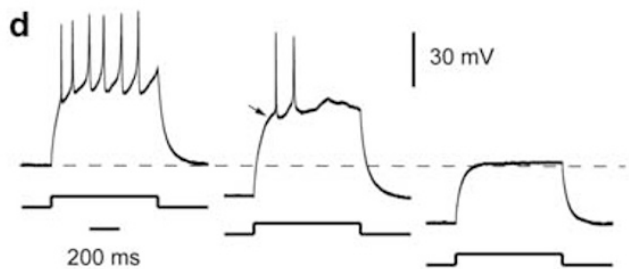

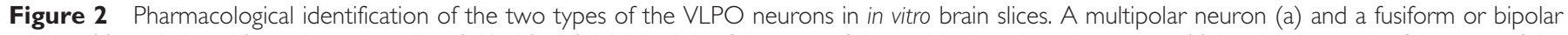

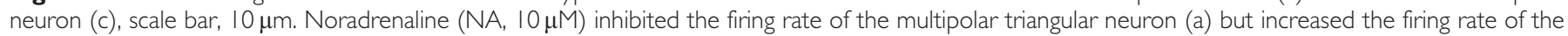

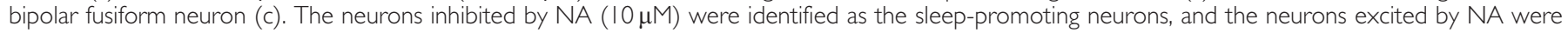

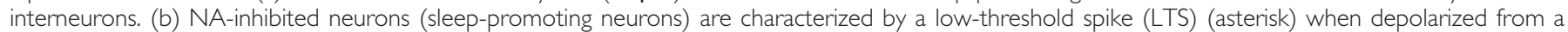

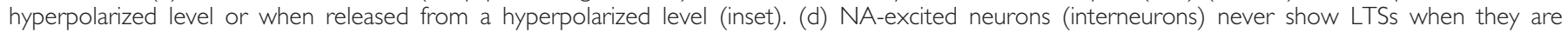

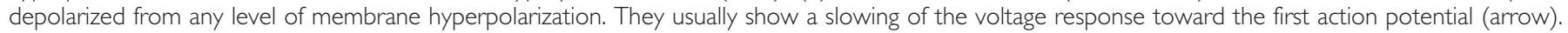

potentials by $10.00 \pm 2.16 \mathrm{mV}$ (from $-43.36 \pm 1.04$ to $-53.36 \pm 2.39 \mathrm{mV}, P<0.01$, respectively, $n=6$, Figure $3 \mathrm{c}$ ). Statistical analysis indicated that morphine hyperpolarized membrane potentials in a dose-dependent manner $(\mathrm{F}(2$, $23)=41.97, P<0.001)$. Morphine at the concentration of $100 \mu \mathrm{M}$ induced greater hyperpolarization than that induced by 10 or $30 \mu \mathrm{M}$ (with followed PLSD test, morphine at the concentration of $100 \mu \mathrm{M}$ vs $10 \mu \mathrm{M},|\mathrm{t}|=7.79$, $P<0.001$; and $100 \mu \mathrm{M}$ vs $30 \mu \mathrm{M},|\mathrm{t}|=8.64, P<0.001$; and $10 \mu \mathrm{M}$ vs $30 \mu \mathrm{M},|\mathrm{t}|=0.35, P=0.731$; Figure $3 \mathrm{~d}$ ).

Morphine at $100 \mu \mathrm{M}$ was found to have no effect on the firing rate or membrane potentials of VLPO interneurons (from $2.34 \pm 0.35$ to $2.19 \pm 0.40 \mathrm{~Hz}, P=0.38$; and from $-45.52 \pm 0.97$ to $-46.33 \pm 1.19 \mathrm{mV}, P=0.07$, respectively, $n=9$, Figure $3 \mathrm{e}$ and $\mathrm{f}$ ).

\section{Effects of Mu and Kappa Receptor on the Inhibitory Effects of Morphine on VLPO Sleep-Promoting Neurons in in vitro Brain Slices}

Under current-clamp conditions, in the presence of TTX, morphine $(10 \mu \mathrm{M})$ was found to induce significant hyperpolarization of sleep-promoting neurons by $6.57 \pm 1.01 \mathrm{mV}$ (from $-47.46 \pm 1.21$ to $-54.03 \pm 1.12 \mathrm{mV}, P<0.01, n=8$, Figure $4 \mathrm{a}$ and $\mathrm{c}$ ), and this effect was blocked by CTOP $(1 \mu \mathrm{M})$, a mu receptor antagonist $(-46.47 \pm 2.49 \mathrm{mV}$ vs $-46.53 \pm 2.80 \mathrm{mV}$ for control, $P=0.86, n=5$, Figure $4 \mathrm{~b}$ and c), suggesting that mu receptors in the VLPO mediate the postsynaptic action of morphine.

A cell-attached configuration was used under currentclamp conditions. In the presence of CTOP $(1 \mu \mathrm{M})$, morphine $(10 \mu \mathrm{M})$ inhibited the firing of sleep-promoting neurons $(n=8$ out of 10 , Figure $4 \mathrm{~d})$. This effect was blocked by nor-BIN (100 nM), a kappa receptor antagonist $(n=9$, Figure $4 \mathrm{e})$. U50488H $(250 \mathrm{nM})$, a kappa receptor agonist, inhibited the firing of sleep-promoting neurons ( $n=9$ out of 12, Figure 4 f). These results indicate that kappa receptors partially mediated the inhibitory effects of morphine.

\section{Effects of Pretreatment with CTOP Microinjected into the VLPO on the Arousal Effects of Morphine Administered Subcutaneously in Rats}

To investigate the involvement of opioid receptors in morphine-induced wakefulness, saline and $\mathrm{mu}$ receptor antagonists were microinjected into the VLPO $15 \mathrm{~min}$ before subcutaneous administration of morphine at 0900 hours. Morphine $(1 \mathrm{mg} / \mathrm{kg})$ injection increased wakefulness by $65.6 \%$ over that observed in the saline group $(136.3 \pm$ $8.9 \mathrm{~min}$ vs $82.3 \pm 1.5 \mathrm{~min}, P<0.001)$, with a decrease in NREM and REM sleep of $55.0 \%(39.4 \pm 7.4 \mathrm{~min}$ vs $87.5 \pm$ $1.7 \mathrm{~min}, P<0.001)$ and $57.4 \%(4.3 \pm 1.7 \mathrm{~min} v \mathrm{~s} 10.2 \pm 1.4 \mathrm{~min}$, $P<0.05)$, respectively, during the $3 \mathrm{~h}$ following subcutaneous injection of saline and morphine $(n=8$, Figure $5 \mathrm{c}-\mathrm{g})$.

When saline or CTOP $(0.05,0.15$, or $0.5 \mathrm{nmol} / \mathrm{side})$ was microinjected into the VLPO at 0845 hours and morphine $(1 \mathrm{mg} / \mathrm{kg}$ ) was injected subcutaneously at 0900 hours, the total time spent in wakefulness and in NREM and REM sleep during the $3 \mathrm{~h}$ after subcutaneous morphine injection was calculated (Figure $5 \mathrm{~g}$ ). CTOP at a dose of $0.05 \mathrm{nmol} / \mathrm{side}$ had no effect on the morphine-induced arousal, as in saline (for wakefulness, $111.6 \pm 5.1 \mathrm{~min} \quad v s \quad 136.3 \pm 8.9 \mathrm{~min}$, $P=0.10$; for NREM sleep, $54.7 \pm 4.1 \mathrm{~min} v s 39.4 \pm 7.4 \mathrm{~min}$, $P=0.17$; and for REM sleep, $13.7 \pm 1.7 \mathrm{~min} v s 4.3 \pm 1.7 \mathrm{~min}$, $P<0.05 ; n=8)$. Microinjection with CTOP at a dose of $0.15 \mathrm{nmol} /$ side decreased morphine-induced wakefulness by $38.4 \% \quad(84.0 \pm 14.8 \mathrm{~min}$ vs $136.3 \pm 8.9 \mathrm{~min}, P<0.01)$ and increased NREM and REM sleep by $96.8 \%(77.5 \pm 11.1 \mathrm{~min}$ vs $39.4 \pm 7.4 \mathrm{~min}, P<0.01)$ and $325.2 \%(18.5 \pm 4.0 \mathrm{~min} v s$ $4.3 \pm 1.7 \mathrm{~min}, P<0.01)$, respectively $(n=7-8)$. Similarly, CTOP at a dose of $0.5 \mathrm{nmol} /$ side decreased wakefulness by $45.9 \%(73.8 \pm 13.7 \mathrm{~min}$ vs $136.3 \pm 8.9 \mathrm{~min}, P<0.001)$ and increased NREM and REM sleep by $107.7 \%$ and $461.2 \%$, respectively $(81.8 \pm 9.1 \mathrm{~min}$ vs $39.4 \pm 7.4 \mathrm{~min}, P<0.01$, and $24.4 \pm 5.7 \mathrm{~min} v s 4.3 \pm 1.7 \mathrm{~min}, P<0.001 ; n=6-8)$. Statistical analysis suggested that pretreatment with microinjection of CTOP into the VLPO blocked the arousal effect of morphine $(1 \mathrm{mg} / \mathrm{kg})$ injected subcutaneously in a dose-dependent 

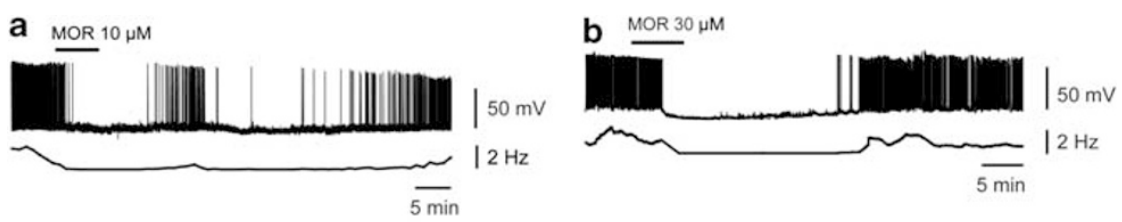

C

d
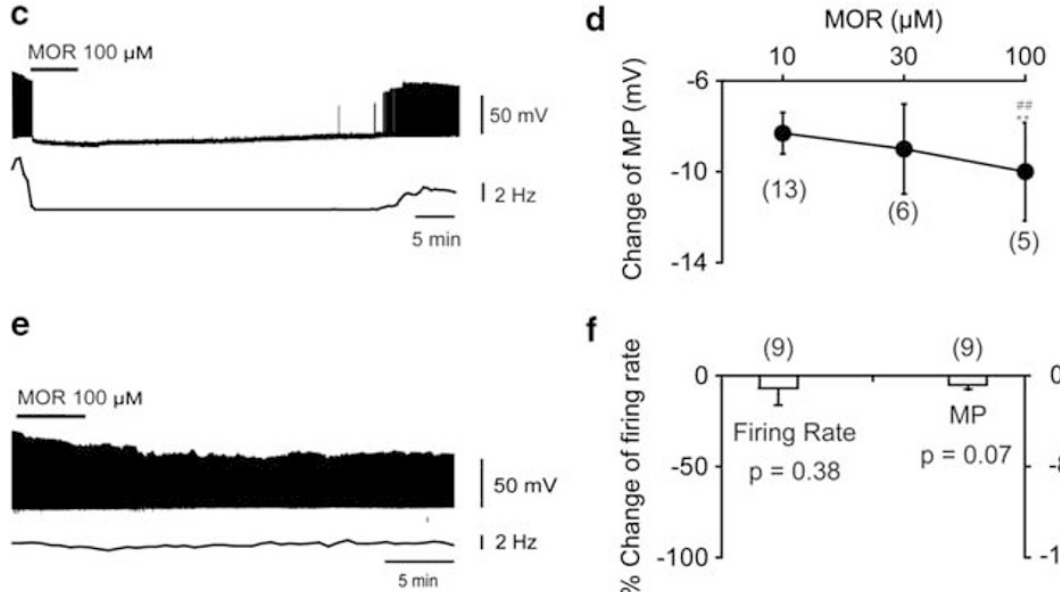

$f$

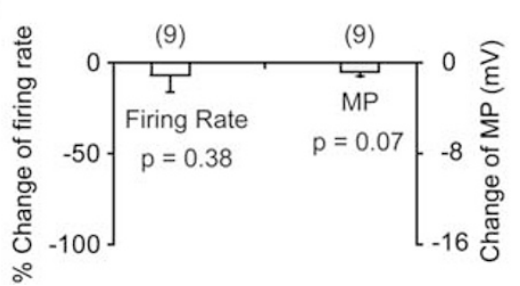

Figure 3 Effects of morphine on the VLPO neurons in in vitro brain slices. (a-d) Morphine inhibited the sleep-promoting neurons. (a-c) Sample traces show the effect of morphine (I0,30, and I00 $\mu \mathrm{M}$ ) on action potential of sleep-promoting neurons. (d) Summary of change in membrane potentials (MPs) of sleep-promoting neurons induced by morphine. ${ }^{*} * P<0.0$ I, significantly different from morphine at a dose of $10 \mu \mathrm{M}$. \#\#P<0.0 I, significantly different from morphine at a dose of $30 \mu \mathrm{M}$. The differences were assessed by ANOVA followed by Fisher's PLSD testing. (e, f) Morphine had no effect on the excitability of interneurons in the VLPO. (e) Sample trace shows the effects of morphine ( $100 \mu M)$ on the action potential of interneurons. (f) Changes in the MPs of interneurons induced by morphine $(100 \mu \mathrm{M})$. The significance was assessed by paired $t$-test. All statistic data were means \pm SEM from the number of independent neurons given in parentheses.
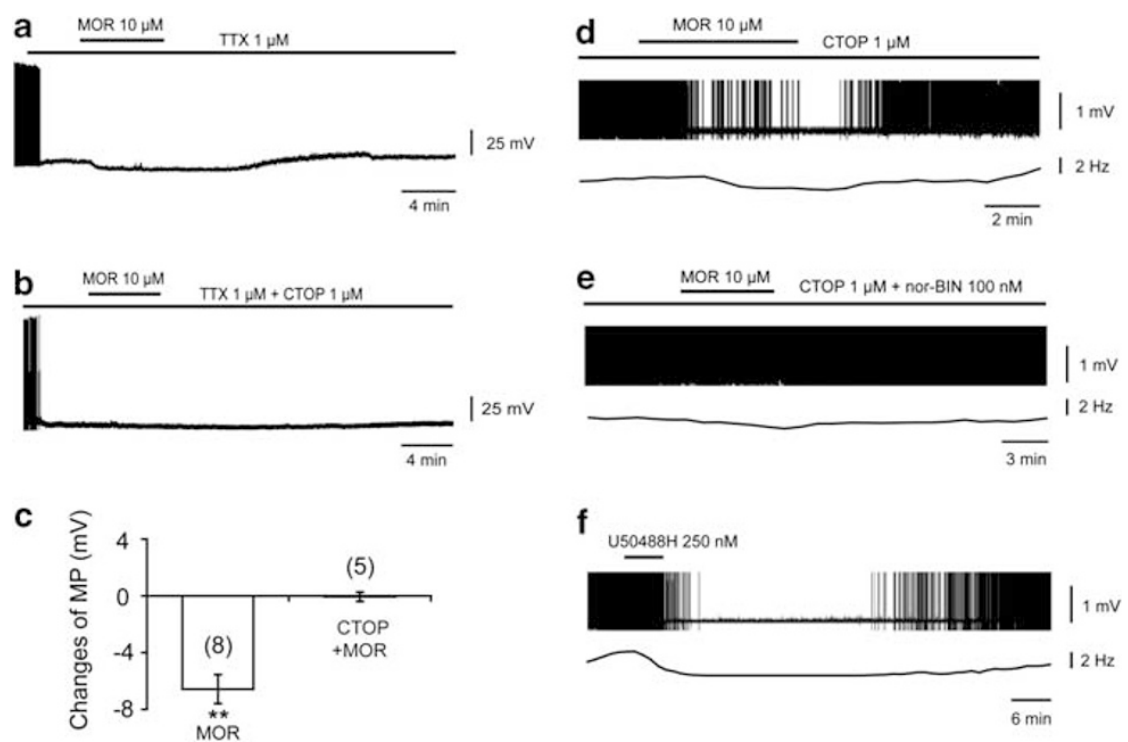

Figure 4 Morphine inhibited sleep-promoting neurons in the VLPO through the synergetic action of mu and kappa receptor in in vitro brain slices. (a-c) Morphine hyperpolarized sleep-promoting neurons by mu receptor. (a, b) Typical sample traces show the effects of morphine (I0 $\mu \mathrm{M})$ on membrane potential (MP) of sleep-promoting neurons in the VLPO and the action of the mu receptor antagonist CTOP (I $\mu M$ ). (c) Summary of hyperpolarization induced by morphine in the absence (control) and presence of CTOP. The recordings were conducted under the presence of TTX (I $\mu \mathrm{M})$. Statistic data were means \pm SEM from the number of independent neurons given in parentheses, **P $<0.0$ l, significantly different from changes of $M P$ in the presence of morphine $(I 0 \mu M)$ and CTOP $(I \mu M)$. The significance was assessed by student's t-test. ( $\mathrm{d}-\mathrm{f})$ Morphine inhibited sleep-promoting neurons partly by affecting the kappa receptor. (d) In the presence of CTOP $(I \mu M)$, morphine $(I 0 \mu \mathrm{M})$ still inhibited the firing of sleep-promoting neurons in the VLPO $(n=8$ of I0). (e) This inhibitory effect was found to be reversed by the kappa receptor antagonist nor-BIN (I00 nM; $n=9)$. (f) Kappa receptor agonist, U50488H $(250 \mathrm{nM})$, inhibited the firing of sleep-promoting neurons ( $n=9$ of 12 )

manner (for wakefulness, $\mathrm{F}(3,25)=6.86, P<0.01$; for NREM and REM sleep, $\mathrm{F}(3,25)=6.12, P<0.01$, and $\mathrm{F}(3$, $25)=6.39, P<0.01$, respectively). The results indicated that the microinjection of CTOP at a dose of $0.5 \mathrm{nmol} / \mathrm{side}$ into the VLPO completely antagonized the arousal effects of morphine $(1 \mathrm{mg} / \mathrm{kg})$.

To determine the contribution of kappa receptors in the VLPO to the arousal effects of morphine, nor-BIN 
a

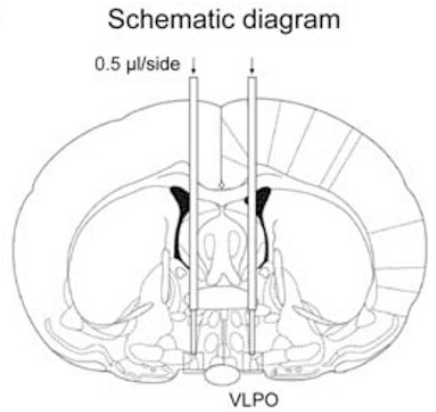

b

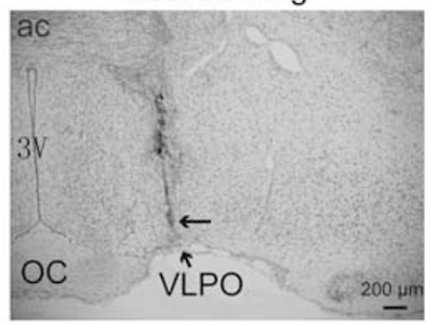

f

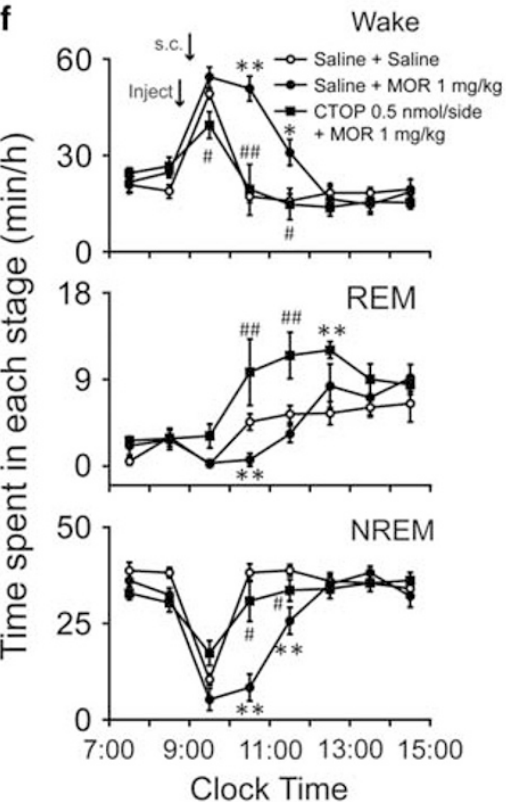

C

e

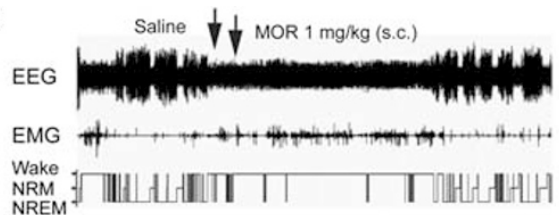

d
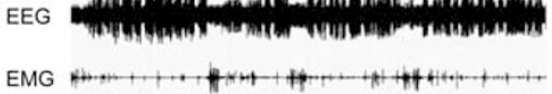

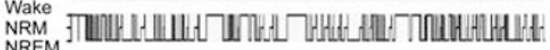
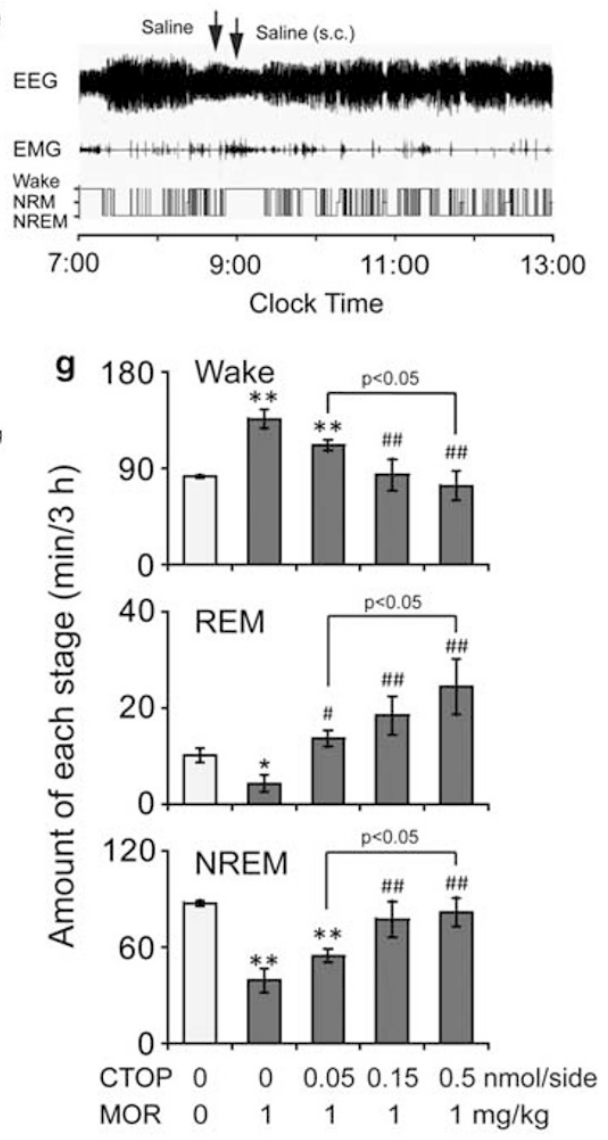

Figure 5 Microinjection of CTOP into the VLPO inhibited the arousal effect of subcutaneously injected morphine. (a, b) The location of guild cannula. (a) Schematic representation of the implantation sites for the guild cannulae $0.5 \mathrm{~mm}$ above the VLPO. The two red rectangles indicate the VLPO areas. (B) Bright-field photomicrograph of a coronal brain section. The VLPO cluster is visualized by Nissl staining as a pyramidal-shaped cell cluster along the ventral surface of the brain, just lateral to the optic chiasm. The black arrow shows the tip of the injector for microinjection. (c-e) Typical examples of polygraphic recordings and corresponding hypnograms in a rat treated with (c) microinjection of saline (at 0845 hours) and subcutaneous morphine (I mg/kg, at 0900 hours) injection, with (d) microinjection of CTOP (0.5 nmol/side, at 0845 hours) and subcutaneous morphine injection (I mg/ $/ \mathrm{kg}$, at 0900 hours), or with (e) microinjection of saline and subcutaneous saline injection. $(f)$ Time course changes of wakefulness and REM and NREM sleep in rats pretreated with microinjection of saline or CTOP $(0.5 \mathrm{nmol} / \mathrm{side})$, followed subcutaneous saline and morphine $(\mathrm{I} \mathrm{mg} / \mathrm{kg})$ injection. Each circle and square represents the hourly mean amount of wakefulness, NREM, and REM sleep. Open and closed circles and closed squares represent the profiles of treatment with saline microinjection after subcutaneous saline injection, saline microinjection after subcutaneous morphine (I mg/kg) injection, and CTOP (0.5 nmol/side) microinjection after subcutaneous morphine $(\mathrm{I} \mathrm{mg} / \mathrm{kg}$ ) injection, respectively. $* P<0.05$; $* * P<0.0 \mathrm{I}$, significantly different from the pretreatment with saline in the VLPO after the subcutaneous saline injection, assessed by paired $t$-test. ${ }^{\#} P<0.05$; ${ }^{\# \#} P<0.0$ I, significantly different from pretreatment with saline in the VLPO, followed the subcutaneous morphine ( $\mathrm{l} \mathrm{mg} / \mathrm{kg}$ ) injection, as assessed by paired $t$-test. ( $\mathrm{g}$ ) Amount of wakefulness and REM and NREM sleep over a 3$\mathrm{h}$ period after subcutaneous saline or morphine $(\mathrm{I} \mathrm{mg} / \mathrm{kg})$ injection, with pretreatment of saline or CTOP $(0.05,0.15$, and $0.5 \mathrm{nmol} / \mathrm{side})$ in the VLPO. $* P<0.05$; $* * P<0.01$, was significantly different from the pretreatment with saline in the VLPO after the subcutaneous saline injection, as assessed by paired t-test. ${ }^{\#} P<0.05 ;{ }^{\#} P<0.01$, significantly different from pretreatment with saline in the VLPO after subcutaneous morphine injection, as assessed by ANOVA followed by Fisher's PLSD test. Values are the means \pm SEM $(n=6-8)$. 
(0.5 or $1.5 \mathrm{pmol} / \mathrm{side}$ ) kappa receptor antagonist was microinjected into VLPO at 0845 hours, $15 \mathrm{~min}$ before subcutaneous injection of morphine $(1 \mathrm{mg} / \mathrm{kg})$ at 0900 hours. The results showed that pretreatment with nor-BIN had no effect on arousal induced by morphine $(1 \mathrm{mg} / \mathrm{kg}$; data not shown).

\section{Effects of Microinjection of CTOP into the VLPO on Physiological Sleep-Wakefulness Architecture}

To investigate the effects of CTOP on physiological sleep-wake behavior, CTOP at a dose of $0.5 \mathrm{nmol} /$ side was microinjected into VLPO at 0900 hours and the total time spent in wakefulness and in NREM and REM sleep during the $6 \mathrm{~h}$ after CTOP microinjection was calculated. As shown in Figure 6, results indicated that CTOP $(0.5 \mathrm{nmol} / \mathrm{side})$ in the VLPO had no significant effects on sleep-wake architecture (for wakefulness, $63.3 \pm 1.5 \mathrm{~min}$ vs $63.4 \pm$ $4.9 \mathrm{~min}$ for the saline-microinjection group, $P=0.98$; for NREM and REM sleep, $96.5 \pm 5.7 \mathrm{~min}$ vs $97.0 \pm 2.4 \mathrm{~min}$, $P=0.94$, and $20.2 \pm 4.8 \mathrm{~min}$ vs $19.6 \pm 3.3 \mathrm{~min}, P=0.92$, respectively; $n=5-6$, Figure $6 \mathrm{~d}$ ). Microinjection of nor-BIN (1.5 pmol/side) into the VLPO had no statistically significant effects on the physiological sleep-wakefulness architecture during the first $6 \mathrm{~h}$ after administration (data not shown).

\section{DISCUSSION}

This study showed that morphine inhibited sleep-promoting neurons in the VLPO through mu and kappa receptors.
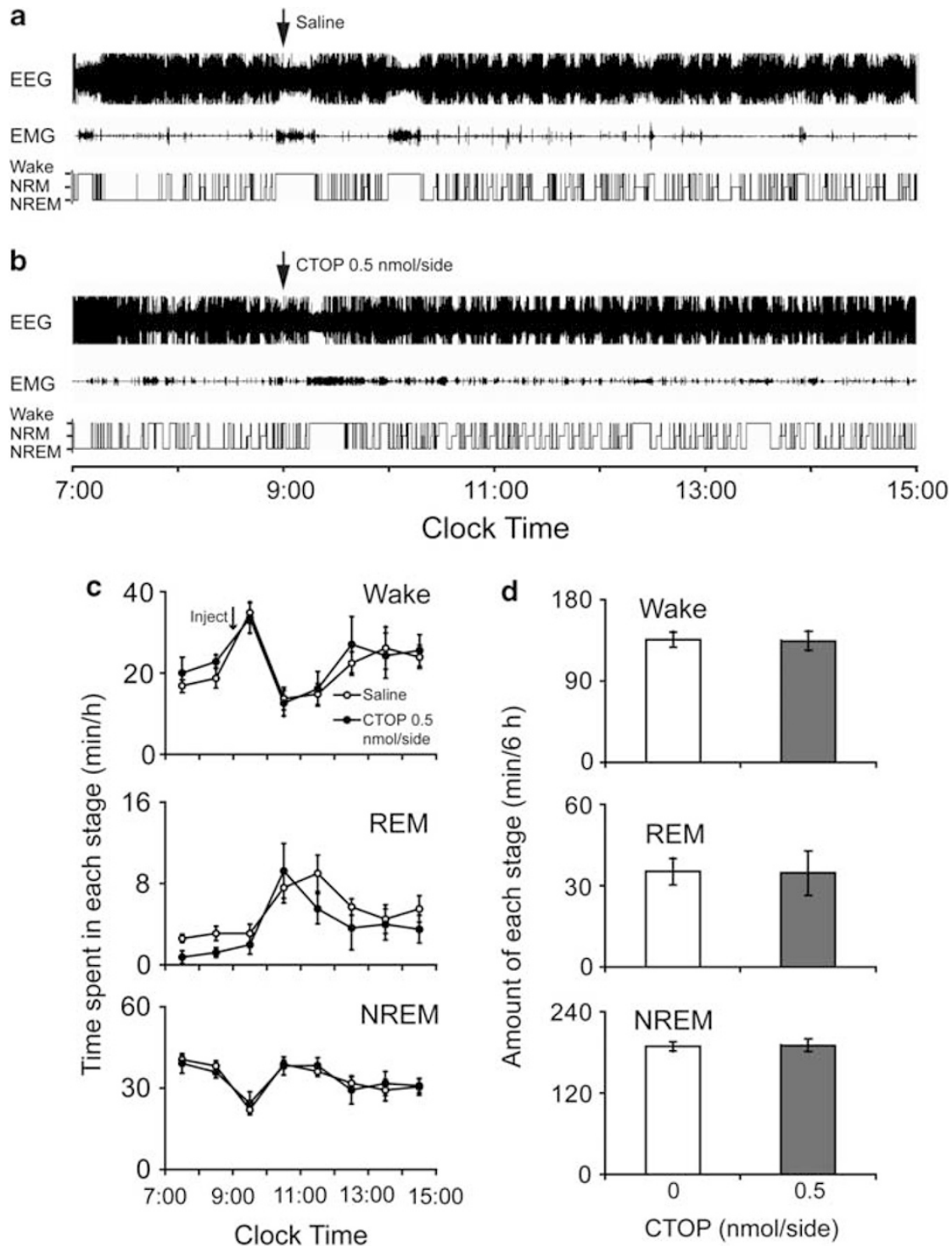

Figure 6 Microinjection of CTOP into the VLPO had no effects on the physiological sleep-wake architecture. (a, b) Typical examples of polygraphic recordings and corresponding hypnograms in a rat treated with microinjection of (a) saline or (b) CTOP (0.5 nmol/side). (c) Time course changes of wakefulness and REM and NREM sleep in rats treated with microinjection of saline or CTOP $(0.5 \mathrm{nmol} / \mathrm{side})$. Open and filled circles represent the profiles for the saline and CTOP $(0.5 \mathrm{nmol} / \mathrm{side})$ treatments, respectively. (d) Amount of wakefulness and REM and NREM sleep over a 6-h period after microinjection of saline or CTOP $(0.5 \mathrm{nmol} / \mathrm{side})$. Open and filled bars represent the profiles for the saline and CTOP (0.5 nmol/side) treatments, respectively. Values are the means $\pm \operatorname{SEM}(n=5-6)$. 
At the systemic level, exogenous morphine exerted an arousal effect. This effect was blocked by pretreatment of VLPO with microinjection of mu but not kappa receptor antagonists. However, mu and kappa receptor antagonists injected into the VLPO did not affect the sleep-wake cycle under baseline conditions. These findings clearly indicate that exogenous morphine inhibits sleep-promoting neurons in the VLPO via mu receptors and induces wakefulness in rats, whereas both mu and kappa receptors are not involved in the physiological regulation of sleep and wakefulness.

In clinical settings, morphine usually interrupts sleep (Dimsdale et al, 2007; Shaw et al, 2005). However, reports on the effects of morphine remain controversial. The systemic or cerebroventricular administration of morphine has been found to inhibit NREM and REM sleep and to increase arousal in rats and cats (de Andres et al, 1984; King et al, 1981; Tortella et al, 1979). Microinjection of morphine into $\mathrm{MPRF}$ in cats or $\mathrm{PnO}$ in rats was found to inhibit NREM and REM sleep, and cholinergic and GABAergic transmission were suppressed (Keifer et al, 1992; Watson et al, 2007). Electrophysiological study revealed that morphine excites the histaminergic arousal system in rats (Eriksson et al, 2000). However, morphine particularly at high doses had a strong sedative effect in human and animals (Hong et al, 1988; Tortella et al, 1978; de Andres et al, 1984; Pickworth and Sharpe, 1979; Matejcek et al, 1988). In humans, morphine at high doses improved sleep in patients with comorbid pain (Adams et al, 2006; Paqueron et al, 2002; Rosenthal et al, 2007). As these patients usually received a high dose of morphine for analgesia, morphine increased sleep in patients with pain may be only a rebound of sleep after pain-induced insomnia, which is referred to patients' pain relieving. In rats, cats, and dogs, after injection of morphine at high doses there was a dissociation of EEG and behavior, where bursts of high-voltage waves were seen over a background of desynchrony; meanwhile the animal was quiet and showed behavioral stupor (Hong et al, 1988; Tortella et al, 1978; de Andres et al, 1984; Pickworth and Sharpe, 1979). Administration of morphine through veins and heart ventricles has been found to increase NREM sleep in beagles (Pickworth et al, 1982). The microinjection of morphine into the noradrenergic locus coeruleus (LC) or nucleus of the solitary was found to increase SWS in cats (Garzon et al, 1995; Reinoso-Barbero and de Andres, 1995). In in vitro mouse brain slices, morphine has been shown to inhibit the orexin arousal system (Li and van den Pol, 2008). Why morphine at high doses induces sedative effects remains unknown. These studies suggest that morphine may affect sleep-wake behavior through multiple pathways in brain. Our findings clearly indicate that morphine suppresses sleep-promoting neurons in the VLPO via mu receptors and so induces wakefulness in rats.

VLPO is one of the most important sleep-promoting centers in the brain (Sherin et al, 1996; Lu et al, 2000; Huang et al, 2007, 2011). It is known to express mu and kappa receptor mRNA (Greco et al, 2008). The VLPO is reciprocally connected with major wake-promoting centers (ie, the ascending arousal system) including, the noradrenergic LC, the histaminergic TMN, the serotoninergic dorsal and median raphe, and the dopaminergic ventral periaqueductal gray (Chou et al, 2002). Many VLPO neurons contain
GABA and galanin, and send inhibitory input to wakepromoting areas (Fort et al, 1998; Luppi et al, 1999; Sherin et al, 1998; Sherin et al, 1996). However, the large majority of VLPO GABAergic neurons are inhibited by neurotransmitters of arousal (ie, NA and acetylcholine; Gallopin et al, 2000). This mutually inhibitory connection may function as a flip-flop switch, allowing rapid transitions between sleep and wakefulness via positive feedback. Our study showed that in brain slices in vitro, morphine inhibited sleeppromoting neurons in the VLPO through the synergistic action of $\mathrm{mu}$ and kappa receptors. Morphine-induced inhibition of sleep-promoting neurons in the VLPO could cause the disinhibition of wake-active neurons, allowing for their own reinforced firing. In this way, morphine can induce arousal by inhibiting sleep-promoting neurons in the VLPO. At the systemic level, blocking the mu receptor in the VLPO can antagonize the arousal effects of morphine, indicating that morphine exerts its arousal effects mainly through the mu receptor in the VLPO.

We found that the kappa receptor agonist inhibited sleep-promoting neurons in the VLPO in brain slices in vitro. However, one previous study showed the microperfusion of kappa receptor agonist into the VLPO for $6 \mathrm{~h}$ increased sleep (Greco et al, 2008). This may have been caused by the diffusion of drugs into nearby structures. The VLPO is a small anatomical structure in the brain. Successive administration in the VLPO can cause drugs diffuse to nearby nuclei or regions in the brain, such as the ventral medial nucleus (VMPO) and the horizontal limb of the diagonal band of broca. The previous reports implied the expression of kappa receptor in the VMPO and diagonal band of broca (DePaoli et al, 1994). The kappa receptor agonist may exert sleep-promoting effects by acting in these areas.

The electrophysiological study showed morphine to inhibit sleep-promoting neurons in the VLPO through synergistic action of mu and kappa receptors. However, in the systemic study, only microinjection of mu receptor antagonist into the VLPO blocked morphine-induced arousal. The kappa receptors in the VLPO did not appear to be involved in the arousal effects of morphine. The discrepancy between in vitro and in vivo assessments remains unexplained.

Microinjection of mu and kappa receptor antagonists into the VLPO had no effect on the physiological sleep-wake cycle. However, morphine systematically injected may reach a higher concentration in the VLPO than endogenous opiates. This morphine mainly functions at mu receptors and inhibits sleep-promoting neurons in the VLPO, so promoting arousal. These results indicate that exogenous morphine exerts arousal effects through the mu receptor in the VLPO, but these receptors have little effect on the regulation of the physiological sleep-wake cycle.

\section{ACKNOWLEDGEMENTS}

This study was supported in part by grants-in-aid for scientific research from the National Basic Research Program of China Grants (2009CB5220004 and 2011CB711000), National Natural Science Foundation of China (30970955, 30901797, 8100569, 31070957, 31171010, 
31171049, 31121061, and 31271164), the Shanghai Committee of Science and Technology (10441901600 and 11ZR1402000), Shanghai Leading Academic Discipline Project (B119), PhD Programs Foundation of Ministry of Education of China (20110071110033), and China National Science and Technology Major Project for Drug Discovery (2009ZX09303-006).

\section{DISCLOSURE}

The authors declare no conflict of interest.

\section{REFERENCES}

Adams EH, Chwiecko P, Ace-Wagoner Y, Mangefrida B, Duerden ME, Perdikis GC et al (2006). A study of AVINZA (morphine sulfate extended-release capsules) for chronic moderate-tosevere noncancer pain conducted under real-world treatment conditions-the ACCPT Study. Pain Pract 6: 254-264.

Chou TC, Bjorkum AA, Gaus SE, Lu J, Scammell TE, Saper CB (2002). Afferents to the ventrolateral preoptic nucleus. J Neurosci 22: 977-990.

de Andres I, Villablanca JR, Burgess JW (1984). Reassessing morphine effects in cats: II. Protracted effects on sleepwakefulness and the EEG. Pharmacol Biochem Behav 21: 923-928.

DePaoli AM, Hurley KM, Yasada K, Reisine T, Bell G (1994). Distribution of kappa opioid receptor mRNA in adult mouse brain: an in situ hybridization histochemistry study. Mol Cell Neurosci 5: 327-335.

Dimsdale JE, Norman D, DeJardin D, Wallace MS (2007). The effect of opioids on sleep architecture. J Clin Sleep Med 3: 33-36.

Eriksson KS, Stevens DR, Haas HL (2000). Opposite modulation of histaminergic neurons by nociceptin and morphine. Neuropharmacology 39: 2492-2498.

Fort P, Gervasoni D, Peyron C, Rampon C, Boissard R, Luppi PH (1998). GABAergic projections to the magnocellular preoptic area and substantia innominata in the rat. Proc Soc Neurosci 28: 3.

Gallopin T, Fort P, Eggermann E, Cauli B, Luppi PH, Rossier J et al (2000). Identification of sleep-promoting neurons in vitro. Nature 404: 992-995.

Gallopin T, Luppi PH, Cauli B, Urade Y, Rossier J, Hayaishi O et al (2005). The endogenous somnogen adenosine excites a subset of sleep-promoting neurons via A2A receptors in the ventrolateral preoptic nucleus. Neuroscience 134: 1377-1390.

Gallopin T, Luppi PH, Rambert FA, Frydman A, Fort P (2004). Effect of the wake-promoting agent modafinil on sleep-promoting neurons from the ventrolateral preoptic nucleus: an in vitro pharmacologic study. Sleep 27: 19-25.

Garzon M, Tejero S, Beneitez AM, de Andres I (1995). Opiate microinjections in the locus coeruleus area of the cat enhance slow wave sleep. Neuropeptides 29: 229-239.

Greco MA, Fuller PM, Jhou TC, Martin-Schild S, Zadina JE, Hu Z et al (2008). Opioidergic projections to sleep-active neurons in the ventrolateral preoptic nucleus. Brain Res 1245: 96-107.

Henry M, Drolet G, Mouginot D (2008). Postsynaptic mu-opioid receptor response in the median preoptic nucleus is altered by a systemic sodium challenge in rats. Eur J Neurosci 27: 1197-1209.

Hong O, Young GA, Khazan N (1988). Modulation of morphineinduced EEG and behavioral effects by dynorphin A-(1-13) in non-tolerant and morphine-tolerant rats. Neuropharmacology 27: 807-812.

Hong ZY, Huang ZL, Qu WM, Eguchi N, Urade Y, Hayaishi O (2005). An adenosine A receptor agonist induces sleep by increasing GABA release in the tuberomammillary nucleus to inhibit histaminergic systems in rats. $J$ Neurochem 92: 1542-1549.

Huang ZL, Qu WM, Li WD, Mochizuki T, Eguchi N, Watanabe T et al (2001). Arousal effect of orexin A depends on activation of the histaminergic system. Proc Natl Acad Sci USA 98: 9965-9970.

Huang ZL, Sato Y, Mochizuki T, Okada T, Qu WM, Yamatodani A et al (2003). Prostaglandin E2 activates the histaminergic system via the EP4 receptor to induce wakefulness in rats. J Neurosci 23: 5975-5983.

Huang ZL, Urade Y, Hayaishi O (2007). Prostaglandins and adenosine in the regulation of sleep and wakefulness. Curr Opin Pharmacol 7: 33-38.

Huang ZL, Urade Y, Hayaishi O (2011). The role of adenosine in the regulation of sleep. Curr Top Med Chem 11: 1047-1057.

Keifer JC, Baghdoyan HA, Lydic R (1992). Sleep disruption and increased apneas after pontine microinjection of morphine. Anesthesiology 77: 973-982.

King C, Masserano JM, Codd E, Byrne WL (1981). Effects of betaendorphin and morphine on the sleep-wakefulness behavior of cats. Sleep 4: 259-262.

Kohtoh S (2008). Algorithm for sleep scoring in experimental animals based on fast Fourier transform power spectrum analysis of the electroencephalogram. Sleep Biol Rhythms 6: 163-171.

Li Y, van den Pol AN (2008). Mu-opioid receptor-mediated depression of the hypothalamic hypocretin/orexin arousal system. J Neurosci 28: 2814-2819.

Lu J, Bjorkum AA, Xu M, Gaus SE, Shiromani PJ, Saper CB (2002). Selective activation of the extended ventrolateral preoptic nucleus during rapid eye movement sleep. J Neurosci 22: 4568-4576.

Lu J, Greco MA, Shiromani P, Saper CB (2000). Effect of lesions of the ventrolateral preoptic nucleus on NREM and REM sleep. J Neurosci 20: 3830-3842.

Luppi PH, Gervasoni D, Peyron C, Rampon C, Barbagli B, Boissard $\mathrm{R}$ et al (1999). Norepinephrine and REM sleep. In: Mallick BNInoue S (eds.) Rapid Eye Movement Sleep. Narosa Publishing House: New Delhi, pp 107-122.

Lydic R, Baghdoyan HA, Lorinc Z (1991). Microdialysis of cat pons reveals enhanced acetylcholine release during state-dependent respiratory depression. Am J Physiol 261: R766-R770.

Lydic R, Keifer JC, Baghdoyan HA, Becker L (1993). Microdialysis of the pontine reticular formation reveals inhibition of acetylcholine release by morphine. Anesthesiology 79: 10031012.

Matejcek M, Pokorny R, Ferber G, Klee H (1988). Effect of morphine on the electroencephalogram and other physiological and other physiological and behavioral parameters. Neuropsychobiology 19: 202-211.

Paqueron X, Lumbroso A, Mergoni P, Aubrun F, Langeron O, Coriat $\mathrm{P}$ et al (2002). Is morphine-induced sedation synonymous with analgesia during intravenous morphine titration? $\mathrm{Br} J$ Anaesth 89: 697-701.

Paxinos G, Watson C (2007). The Rat Brain in Stereotaxic Coordinates. 6th edn. Academic Press: San Diego.

Pickworth WB, Sharpe LG (1979). EEG-behavioral dissociation after morphine-and cyclazocine-like drugs in the dog: further evidence for two opiate receptors. Neuropharmacology 18: 617-622.

Pickworth WB, Sharpe LG, Gupta VN (1982). Morphine-like effects of clonidine on the EEG, slow wave sleep and behavior in the dog. Eur J Pharmacol 81: 551-557.

Raehal KM, Bohn LM (2005). Mu opioid receptor regulation and opiate responsiveness. AAPS J 7: E587-E591.

Reinoso-Barbero F, de Andres I (1995). Effects of opioid microinjections in the nucleus of the solitary tract on the sleepwakefulness cycle states in cats. Anesthesiology 82: 144-152. 
Rosenthal M, Moore P, Groves E, Iwan T, Schlosser LG, Dziewanowska Z et al (2007). Sleep improves when patients with chronic OA pain are managed with morning dosing of once a day extended-release morphine sulfate (AVINZA): findings from a pilot study. J Opioid Manag 3: 145-154.

Shaw IR, Lavigne G, Mayer P, Choiniere M (2005). Acute intravenous administration of morphine perturbs sleep architecture in healthy pain-free young adults: a preliminary study. Sleep 28: 677-682.

Sherin JE, Elmquist JK, Torrealba F, Saper CB (1998). Innervation of histaminergic tuberomammillary neurons by GABAergic and galaninergic neurons in the ventrolateral preoptic nucleus of the rat. J Neurosci 18: 4705-4721.

Sherin JE, Shiromani PJ, McCarley RW, Saper CB (1996). Activation of ventrolateral preoptic neurons during sleep. Science 271: 216-219.

Szymusiak R, Alam N, Steininger TL, McGinty D (1998). Sleepwaking discharge patterns of ventrolateral preoptic/anterior hypothalamic neurons in rats. Brain Res 803: 178-188.
Tortella FC, Moreton JE, Khazan N (1978). Electroencephalographic and behavioral effects of D-ala2-methionine-enkephalinamide and morphine in the rat. J Pharmacol Exp Ther 206: 636-643.

Tortella FC, Moreton JE, Khazan N (1979). Electroencephalographic and behavioral tolerance to and cross-tolerance between D-Ala2-methionine-enkephalinamide and morphine in the rat. J Pharmacol Exp Ther 210: 174-179.

Wang YQ, Tu ZC, Xu XY, Qu WM, Urade Y, Huang ZL (2012). Acute administration of fluoxetine normalizes rapid eye movement sleep abnormality, but not depressive behaviors in olfactory bulbectomized rats. J Neurochem 120: 314-324.

Watson CJ, Lydic R, Baghdoyan HA (2007). Sleep and GABA levels in the oral part of rat pontine reticular formation are decreased by local and systemic administration of morphine. Neuroscience 144: 375-386.

Ye JH, Zhang J, Xiao C, Kong JQ (2006). Patch-clamp studies in the CNS illustrate a simple new method for obtaining viable neurons in rat brain slices: glycerol replacement of $\mathrm{NaCl}$ protects $\mathrm{CNS}$ neurons. J Neurosci Methods 158: 251-259. 